\title{
Seleção de iniciadores moleculares ISSR para estudos de variabilidade genética da Syagrus cearensis Noblick
}

\author{
Abidã Gênesis da Silva Neves ${ }^{1 *}$, Kyvia Pontes Teixeira das Chagas ${ }^{1}$, Raiane Pereira de Sales ${ }^{1}$, Malcon \\ do Prado Costa ${ }^{1}$, Cristiane Gouvêa Fajardo ${ }^{1}$, Fábio de Almeida Vieira ${ }^{1}$
}

\begin{abstract}
RESUMO: Syagrus cearensis Noblick, é uma espécie nativa com distribuição na região nordeste brasileiro. É utilizada na indústria alimentícia, cosméticos, forragem, medicinal e uso paisagístico. Devido sua importância econômica e exploração extrativista, tornam-se necessárias estratégias de conservação de germoplasma e seleção de genótipos superiores, contribuindo com a perpetuação da espécie. Nesse sentido, a seleção de marcadores moleculares proporciona a caracterização genética populacional, gerando informações para conservação da espécie. Assim, objetivou-se selecionar marcadores ISSR para futuras análises de diversidade genética de populações naturais da espécie. Foram coletadas amostras foliares de 20 indivíduos na Unidade Acadêmica Especializada em Ciências Agrárias (UECIA) da Universidade Federal do Rio Grande do Norte (UFRN), município Macaíba/RN. Foram testados trinta iniciadores e destes selecionados doze, que se destacaram por apresentarem maior número de locos com melhor visualização. Foram identificados 118 locos, para os trinta iniciadores. Os selecionados foram UBC807, UBC808, UBC818, UBC840, UBC841, UBC851, UBC852, UBC857, UBC859, UBC860, UBC880, M1, fornecendo um total de 66 locos. Os marcadores ISSR empregados neste estudo demonstraram eficiência na detecção de locos que permitirão analisar os polimorfismos moleculares para Syagrus cearensis. Por meio dos estudos da diversidade genética dos indivíduos, será possível estabelecer estratégias que visem à conservação e manutenção da espécie.
\end{abstract}

Palavras-chave: Conservação, diversidade, catolé.

\section{Selection of ISSR molecular primers for genetic variability studies of Syagrus cearensis Noblick}

ABSTRACT: Syagrus cearensis Noblick, is a native species with distribution in the Brazilian northeast region. It is used in the food industry, cosmetics, fodder, medicinal and landscape use. Due to its economic importance and extractive exploitation, strategies of conservation of germplasm and selection of superior genotypes are necessary, contributing to the perpetuation of the species. In this sense, the selection of molecular markers provides the population genetic characterization, generating information for the conservation of the species. Thus, we aimed to select ISSR markers for future analyzes of genetic diversity of natural populations of the species. Leaf samples were collected from 20 individuals at the Unidade Acadêmica Especializada em Ciências Agrárias (UECIA) of the Universidade Federal do Rio Grande do Norte (UFRN), in the municipality of Macaíba/RN. Thirty primers were tested and twelve were selected, which stood out because they presented higher number of loci with better visualization. Eleven foci were identified for the thirty primers. The selected were UBC807, UBC808, UBC840, UBC840, UBC841, UBC851, UBC852, UBC857, UBC859, UBC860, UBC880, M1, providing a total of 66 loci. The ISSR markers used in this study demonstrated efficiency in the detection of loci that will allow to analyze the molecular polymorphisms for Syagrus cearensis. Through the studies of the genetic diversity of individuals, it will be possible to establish strategies that aim at the conservation and maintenance of the species.

Keywords: conservation, diversity, catolé.

\section{INTRODUÇÃO}

A família das palmeiras, Arecaceae, forma um dos principais troncos da evolução das monocotiledôneas, sendo constituída atualmente por 252 gêneros e aproximadamente de 2.600 espécies (DRANSFIELD et al. 2008). No Brasil, a família Arecaceae apresenta naturalmente 38 gêneros e cerca de 270 espécies (LORENZI et al. 2010), com ampla distribuição nas regiões brasileiras, tais como no Norte (Tocantins), Nordeste (Bahia, Ceará, Paraíba, e Pernambuco), Centro-Oeste (Distrito
Federal, Goiás, Mato Grosso e Mato Grosso do Sul), Sudeste (Minas Gerais, Espírito Santo e Rio de Janeiro, São Paulo) e Sul (Paraná), compondo principalmente os domínios fitogeográficos Mata Atlântica e Caatinga (LORENZI et al., 2010; FLORA DO BRASIL 2020, 2019). A Syagrus cearensis (Figura 1), conhecida popularmente como catolé, coco catolé, coco-babão ou babão é uma palmeira, que detém uma grande diversidade quanto a sua utilização (ARAÚJO SILVA-CARDOSO et al., 2017). Dentre eles, confecções de artigos

\footnotetext{
Recebido em 05/10/2019, Aceito para publicação em 15/10/2019

${ }^{1}$ Universidade Federal do Rio Grande do Norte

*e-mail: abidagenesis@hotmail.com
} 
regionais tais como: chapéus de palha, vassouras, bolsas (folhas); banquetas de decoração (tronco); ração animal, na culinária, leite, óleo, (extração das amêndoas). Além de uso terapêutico no tratamento de problema de estômago, erisipela, diarreia e diurético (ROSA et al., 2012).

Araújo Silva-Cardoso et al. (2017) alertaram que devido ao aumento da importância econômica da espécie, combinada com a intensa exploração extrativa e o avanço indiscriminado do desmatamento, são necessários estudos e tecnologias, como conservação, manejo e seleção de genótipos superiores, bem como desenvolver métodos de propagação, a fim de assegurar condições para o desenvolvimento de programas de melhoramento genético da espécie.

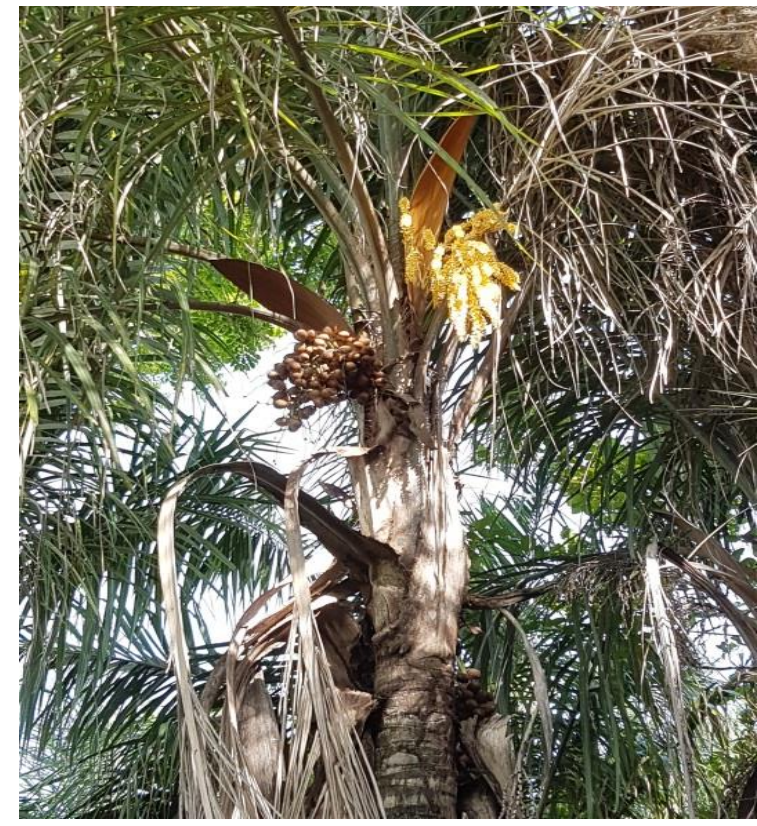

Figura 1 - Indivíduo de Syagrus cearensis emitindo os botões florais, e os frutos verdes característicos.

Fleury (2003) afirmou que para a conservação da população da espécie do mesmo gênero, Syagrus romanzoffiana (Cham.) Glassman, em fragmentos florestais com área inferior a 1.000 ha, são necessários planos de manejo, como medidas que tenham por objetivo o desenvolvimento de subbosques em fragmentos que estejam inteiramente sob o efeito de borda, e a predação de sementes pósdispersas em fragmentos, onde haja forte pressão de predadores de sementes.

As características morfológicas de uma espécie são muito utilizadas para a caracterização. No entanto, os marcadores moleculares fornecem uma abordagem mais minuciosa de cada indivíduo e são muito eficientes para a determinação da variabilidade genética, por analisarem diretamente o material genético (YANAKA et al., 2005).

Neste sentido, vários estudos que têm como objetivo analisar a variabilidade genética em populações vem empregando os marcadores moleculares ISSRs (Inter Simple Sequence Repeat), pois são eficazes na detecção de polimorfismo, têm baixo custo, são abundantes no genoma e reprodutíveis entre laboratórios (FAJARDO et al., 2018; SANTANA et al., 2011; SILVA et al., 2017; PINHEIRO et al., 2017). Esta constitui uma técnica que não necessita de conhecimento prévio do genoma da espécie alvo de estudo, gerando elevado número de locos polimórficos e alta reprodutibilidade (ADHIKARI et al., 2017; SANTOS et al., 2011).

Assim, o presente estudo teve como objetivo selecionar os marcadores ISSR para futuras análises de diversidade genética de populações naturais de Syagrus cearensis Noblick.

\section{MATERIAL E MÉTODOS}

Foram coletadas amostras foliares de 20 indivíduos (Figura 2) representantes de uma população natural situadas na Unidade Acadêmica Especializada em Ciências Agrárias (UECIA) da Universidade Federal do Rio Grande do Norte (UFRN), nas coordenadas $5^{\circ} 52^{\prime} 58^{\prime \prime}$ S e $35^{\circ} 21^{\prime} 47^{\prime \prime}$ $\mathrm{N}$, no município de Macaíba, $\mathrm{RN}$.

Foram realizadas coletas de fragmentos do tecido foliar dos indivíduos e adicionados em tubos plásticos contendo $2 \mathrm{ml}$ de CTAB $2 \mathrm{x}$, sendo logo após, transportados ao laboratório e armazenados em freezer à $-20^{\circ} \mathrm{C}$, até dar início a extração do DNA, por meio de um protocolo pré-estabelecido (DOYLE, DOYLE, 1987).

Aproximadamente $250 \mathrm{mg}$ de material foliar foram utilizadas para a extração do DNA pelo método CTAB proposto por Doyle e Doyle (1987), com algumas alterações. Foram utilizados $100 \mathrm{mM}$ de Tris $\mathrm{pH} 8,0 ; 1,4 \mathrm{M}$ de $\mathrm{NaCl} ; 20 \mathrm{mM}$ de EDTA $\mathrm{pH} 8,0 ; 2 \%(\mathrm{p} / \mathrm{v})$ CTAB; $1 \%$ (p/v) PVP-40 e $0,2 \%$ (v/v) de $\beta$-mercaptoetanol pré-aquecido a $60^{\circ} \mathrm{C}$ em banho-maria. O DNA foi então conduzido à geladeira e submetido a uma temperatura média de $4^{\circ} \mathrm{C}$, até que o pellet solubilizasse na solução. Posteriormente foi armazenado em freezer até sua utilização. Após sua extração, a concentração total de DNA foi mensurada utilizando o espectrofotômetro Epoch ${ }^{\mathrm{TM}}$. 


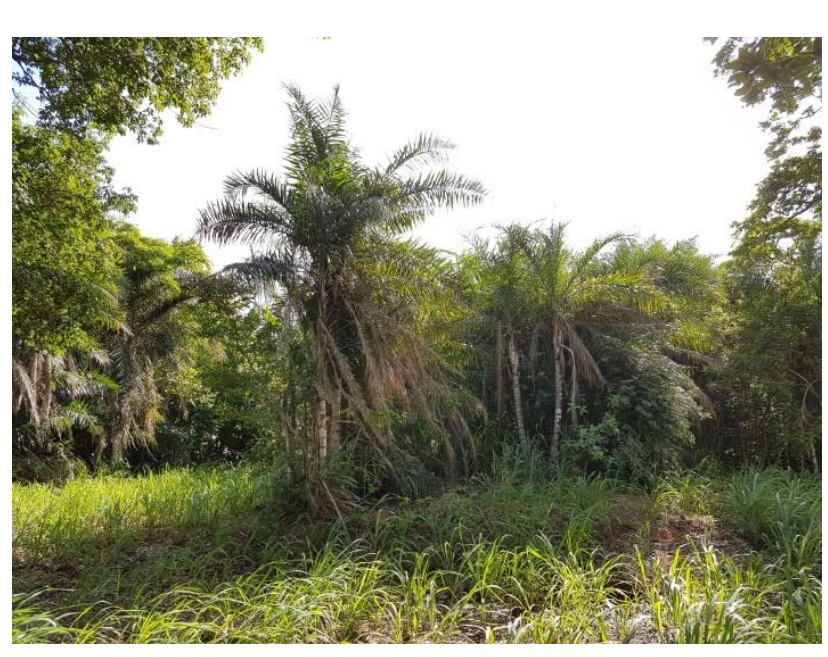

Figura 2 - População natural de Syagrus cearensis representante da unidade amostral estudada.

Nas reações de PCR foram utilizados 30 iniciadores ISSR da Universidade de British Columbia (UBC primer set \#9, Vancouver, Canadá). O mix de PCR foi constituído de Buffer (10 X), BSA (1,0 mg ml$\left.{ }^{-1}\right), \operatorname{MgCl}_{2}(50 \mathrm{mM})$, dNTP (2,5 $\mathrm{mM})$, primer $(2 \mu \mathrm{M})$, Taq polimerase $\left(\mathrm{U} \mu \mathrm{l}^{-1}\right)$, DNA (diluído 1:50) e água ultra pura, em um volume final de $12 \mu 1$ por amostra.

Para a seleção dos iniciadores, foi feito um "bulk" misturando-se $4 \mu \mathrm{L}$ de DNA concentrado de três indivíduos para possibilitar o aumentando das chances de amplificação de locos.

As PCRs foram realizadas em termociclador automático Biocycler, no qual as amostras foram inicialmente, desnaturadas a $94^{\circ} \mathrm{C}$ por $2 \mathrm{~min}$, seguidos de 37 ciclos, iniciando-se com 15 segundos a $94^{\circ} \mathrm{C}$; em seguida 30 segundos a $47^{\circ} \mathrm{C}$ e posteriormente $72{ }^{\circ} \mathrm{C}$ por 1 minuto; ao final de todos os ciclos o processo foi finalizado por 7 minutos a $72^{\circ} \mathrm{C}$ e resfriado a $4^{\circ} \mathrm{C}$.

Posteriormente à PCR, foi realizada a eletroforese em gel de agarose a 1,5\% (p/v), com tampão TAE 1X (Tris-Acetato EDTA), com a voltagem de $100 \mathrm{~V}$, por duas horas e meia. Foi utilizado o marcador de DNA (ladder) de 1000 pares de bases para determinar o tamanho molecular dos fragmentos amplificados. Ao término da eletroforese, os géis foram fotografados mediante fonte de luz ultravioleta e fotografados com auxílio do sistema de com o auxílio do sistema de foto documentação E-Box VX2. Assim, os iniciadores foram comparados e selecionados, visto que aqueles que apresentaram melhor definição e maiores números de locos amplificados estavam dentro do critério de inclusão. Todavia, os que não apresentaram tais caracteres foram desconsiderados.

\section{RESULTADOS E DISCUSSÕES}

A metodologia aplicada foi eficiente, mostrando uma boa amplificação das bandas e locos, resultando em uma adequada definição.

Dos trinta iniciadores testados para averiguar a capacidade de gerar bandas, doze destacaram-se por apresentarem melhor amplificação e proporcionaram um maior quantitativo de locos. Os doze iniciadores selecionados apresentaram 66 locos, sendo eles, UBC807, UBC808, UBC818, UBC840, UBC841, UBC851, UBC852, UBC857, UBC859, UBC860, UBC880, M1. A quantidade de bandas por iniciador variou de quatro (UBC118) a sete (UBC807). Os iniciadores UBC822, UBC829, UBC881 não amplificaram (Figura 3).

Pinto et al. (2015) realizaram a caracterização molecular do híbrido Syagrus costae (Syagrus oleracea X Syagrus coronata). Neste estudo foram selecionados também doze iniciadores de ISSR, que se mostraram eficazes para descriminação dos híbridos.

Dos 118 locos obtidos, $42 \%$ dos iniciadores geraram de 5 a 7 locos, $42 \%$ forneceram de 2 a 4 locos e $16 \%$ obtiveram um loco ou não amplificaram. Duarte (2015) salientou que entre os iniciadores selecionados, o UBC 857 foi altamente eficiente, sendo também comprovado para espécie Ficus bonijesuslapensis, fomentando estudos que tenham como base a seleção dos iniciadores ISSRs.

Conforme a literatura, encontram-se diversos trabalhos utilizando marcadores dominantes (CARVALHO et al., 2012; FAJARDO et al., 2018; SILVA et al., 2017; PINHEIRO et al., 2017), incluindo os ISSR que consideram a quantidade de locos polimórficos a diversidade genética.

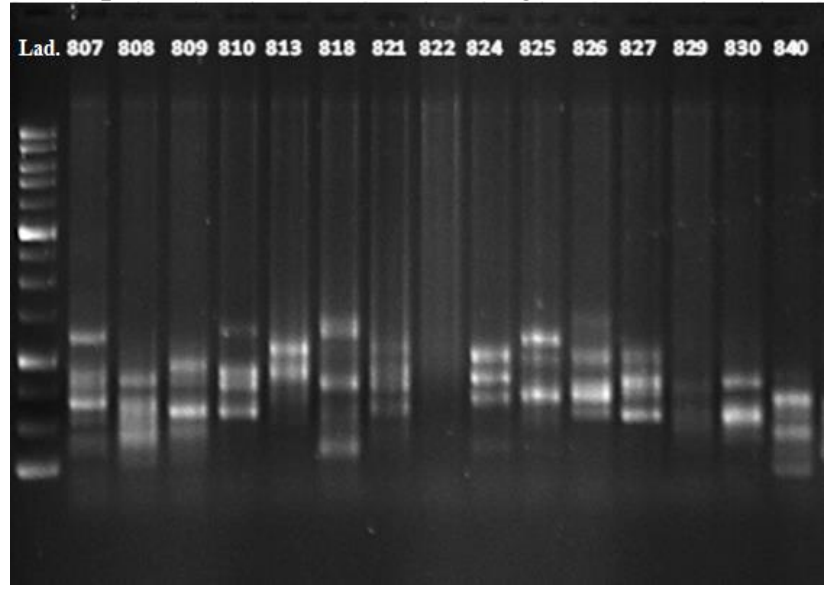




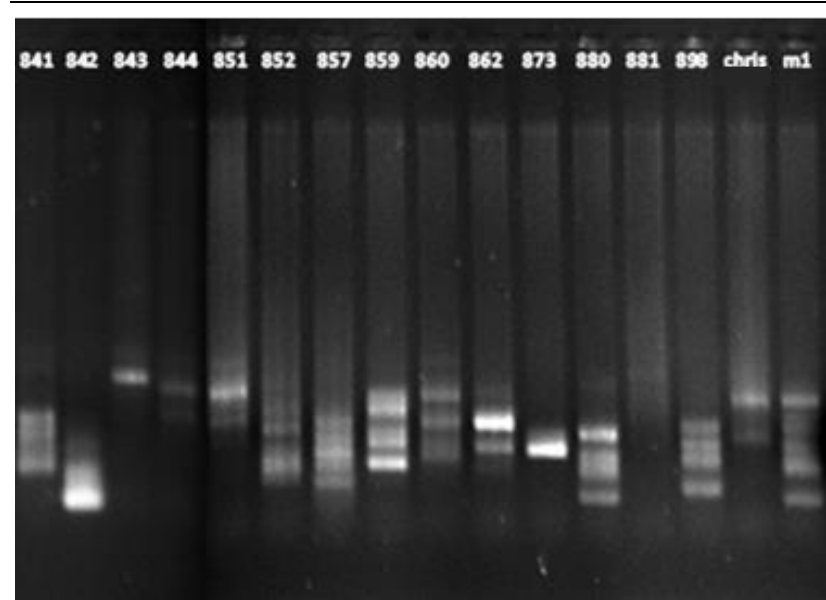

Figura 3 - Produto da amplificação dos fragmentos, gerados pelos 31 iniciadores ISSRs para estudos de diversidade genética.

\section{CONCLUSÕES}

Os doze marcadores ISSR selecionados no estudo foram eficientes para a Syagrus cearensis possibilitando a identificação do polimorfismo molecular, proporcionando estudos futuros quanto à diversidade, melhoramento e conservação genética.

\section{REFERÊNCIAS BIBLIOGRÁFICAS}

ADHIKARI, S. et al. Application of molecular markers in plant genome analysis: A review. The Nucleus, v. 60, n. 3, p. 283-297, 2017.

ARAÚJO SILVA-CARDOSO, I. M.; SOUZA, A. M.; SCHERWINSKI-PEREIRA, J. E. The palm tree Syagrus oleracea Mart. (Becc.): A review. Scientia Horticulturae, v. 225, p. 65-73, 2017.

CARVALHO, R.S.; PINTO, J.F.N.; REIS, E.F.; SANTOS, S.C.; DIAS, L.A.S. Variabilidade genética de cajuzinho-do-cerrado (Anacardium humile St. Hill.) por meio de marcadores RAPD, Revista Brasileira de Fruticultura, Jaboticabal, v. 34, n. 1, p. 227-233, 2012.

DRANSFIELD, J.; UHL, N.W.; ASMUSSEN, C.B.; BAKER, W.J.; HARLEY, M.M. \& LEWIS, C.E. 2008. Genera Palmarum: the evolution and classification of palms. Kew Publishing, Royal Botanical Garden, Londres. 732p.

DOYLE, J. J.; DOYLE, J. L. Isolation of plant DNA from fresh tissue. Focus, v.12, n.1, p.13-15, 1987.

DUARTE, J. F.; CARVALHO, D.; VIEIRA, F. A. Genetic conservation of Ficus bonijesulapensis R.M. Castro in a dry forest on limestone outcrops. Biochemical Systematics and Ecology, v.59, p.54-62, 2015.

FAJARDO, C. G. et al . Genetic diversity in natural populations of Hancornia speciosa Gomes: implications for conservation of genetic resources. Ciência e Agrotecnologia, v. 42, n. 6, p. 623-630, 2018.
FLEURY, M. Efeito da Fragmentação Florestal na Predação de Sementes da Palmeira Jerivá (Syagrus romanzoffiana) em Florestas Semidecíduas do Estado de São Paulo. Dissertação de Mestrado. Piracicaba, SP: Escolla Superior de Agricultura "Luiz de Queiroz", Universidade de São Paulo, 2003.

FLORA DO BRASIL $2020 \quad$ EM CONSTRUÇÃO. Jardim Botânico do Rio de Janeiro. Disponível em: <http://floradobrasil.jbrj.gov.br/ >. Acesso em: 01 Mar. 2019.

LORENZI, H., NOBLICK, L. R., KAHN, F., FERREIRA, E. Flora brasileira-Arecaceae (palmeiras) Flora Brasileira -Arecaceae (palmeiras). Nova Odessa: Plantarum, 384p., 2010.

PINHEIRO, L. G.; CHAGAS, K. P. T.; FREIRE, A. S. M.; FERREIRA, M. C.; FAJARDO, C. G.; VIEIRA, F. A. Anthropization as a determinant factor in the genetic structure of Copernicia prunifera (Arecaceae). Genetics and Molecular Research, v. 16, p. 1-14, 2017.

PINTO, J. F. N.; REIS, E. F.; DOS SANTOS, E. A. Caracterização molecular do híbrido Syagrus costae em relação aos seus parentais guariroba e licuri. In: Congresso Brasileiro de Melhoramento de PlantasCBMP. 2015. Disponível em: < http://www.sbmp.org.br/8congresso/anais/resumos/resAn exo1-0768-0408.pdf >. Acesso em: 01 de mar. 2019.

ROSA, J.; JESUS, D.; DUARTE, F.; LIMA, A.; PEREIRA, V. Otimização e validação de estratégias analíticas para avaliação do teor do leite de coco do catolé. Disponível em:< http://connepi.ifal.edu.br/ocs/index.php/connepi/CONNE PI2010/paper/viewFile/81/124 > Acessado em: 03/03/2012.

SANTOS, L. F.; OLIVEIRA, E. J.; SILVA, A. S. ISSR Markers as a tool for the assessment of genetic diversity in Passiflora. Biochemical Genetics, Dordrecht, n. 49, p. 540-554, 2011.

SILVA, R. A. R.; PINHEIRO, L. G.; CHAGAS, K. P. T.; FREIRE, A. S. M.; SANTOS, J. R. M.; VIEIRA, F. A. Características biométricas dos frutos e sementes da palmeira Copernicia prunifera (Arecaceae). Revista de Ciências Agro-Ambientais. v.15, p.144-149, 2017.

YANAKA, F. Y. et al. Variabilidade genética em populações naturais de Bromus auleticus Tris. Ex Ness (Poaceae) com base em isoenzimas e marcadores RAPD. Revista Brasileira de Zootecnia, v.34, n.6, p.1897-1904, 2005. 